\title{
"Uma reunião de carreiras de cavalos": lazer, esporte e os paradoxos da modernidade no Rio Grande do Sul, séculos XIX e XX
}

\author{
João Manuel Casquinha Malaia Santos ${ }^{1 *}$ \\ ${ }^{1}$ Universidade Federal de Santa Maria, Santa Maria/ RS - Brasil \\ Jonas Moreira Vargas ${ }^{2 *}$ \\ ${ }^{2}$ Universidade Federal de Pelotas, Pelotas/ RS - Brasil \\ José Martinho Rodrigues Remedi ${ }^{* * *}$ \\ ${ }^{3}$ Universidade Federal de Santa Maria, Santa Maria/ RS - Brasil
}

\section{RESUMO}

A proposta deste artigo é analisar o fenômeno lúdico das carreiras em cancha reta, corridas de cavalo que acontecem pelo menos desde o século XIX no Sul do Brasil. Procura-se compreender este fenômeno como uma face oculta de uma modernidade simbolizada pelos clubes de corridas de cavalos que se instauraram nas grandes cidades brasileiras a partir da segunda metade do século XIX. Tal análise faz-se a partir de fontes variadas como a literatura, documentos governamentais, periódicos e processos-crime. A partir desta variada documentação, pode-se perceber a perenidade deste fenômeno que se transformou em símbolo cultural da região, sendo atualmente patrimônio histórico do Rio Grande do Sul. Palavras-chave: lazer; esporte; modernidade; cavalos; Rio Grande do Sul.

DOI: http://dx.doi.org/10.1590/2237-101X02104507

Artigo recebido em 12 de setembro de 2019 e aceito para publicação em 10 de fevereiro de 2020 .

* Professor da Universidade Federal de Santa Maria / Centro de Ciências Sociais e Humanas / Departamento de História, Santa Maria/ RS - Brasil. E-mail: jmalaia@gmail.com. ORCID: https://orcid.org/0000-00017154-3860.

** Professor da Universidade Federal de Pelotas / Instituto de Ciências Humanas / Departamento de História, Pelotas/ RS - Brasil. E-mail: jonasmvargas@yahoo.com.br. ORCID: https://orcid.org/0000-0003-11976933.

*** Professor da Universidade Federal de Santa Maria / Centro de Ciências Sociais e Humanas / Departamento de História, Santa Maria/ RS - Brasil. E-mail: jose.remedi@gmail.com. ORCID: https://orcid. org/0000-0003-1662-9754. 


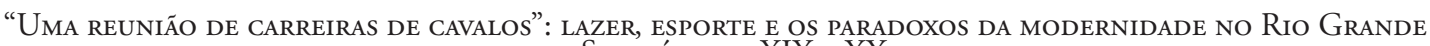
DO SUl, SÉCUlOS XIX E XX

João Manuel Casquinha Malaia Santos, Jonas Moreira Vargas e José Martinho Rodrigues Remedi

\title{
"A meeting of horse races": leisure, sport and the paradoxes of modernity in Rio Grande do Sul, 19th and 20th centuries
}

\begin{abstract}
The purpose of this paper is to analyze the leisure phenomenon of straight-legged horse racing that have been taking place at least since the 19th century in southern Brazil. We seek to understand this phenomenon as a modernity hidden face, symbolized by the horse racing clubs that were established in Brazilian large cities from the second half of the 19th century. Such analysis is made from various sources such as literature, government documents, newspapers, magazines and criminal proceedings. From this varied documentation, we can see the perenniality of this phenomenon that has become a cultural symbol of the region, and is currently a historical heritage of Rio Grande do Sul.
\end{abstract}

Keywords: leisure; sport; modernity; horses; Rio Grande do Sul.

\section{"Una reunión de carreras de caballos": ocio, deporte y las paradojas de la modernidad en Rio Grande do Sul, siglos XIX y XX}

\section{RESUMEN}

El propósito de este trabajo es analizar el fenómeno lúdico de las carreras cuadreras, las carreras de caballos que se han llevado a cabo al menos desde el siglo XIX en el sur de Brasil. Buscamos entender este fenómeno como un lado oculto de una modernidad simbolizada por los clubes de carreras de caballos que se establecieron en las grandes ciudades brasileñas de la segunda mitad del siglo XIX. Dicho análisis se realiza a partir de diversas fuentes, como literatura, documentos gubernamentales, periodicos y procedimientos penales. A partir de esta variada documentación, podemos ver la perennedad de este fenómeno que se ha convertido en un símbolo cultural de la región y que actualmente es un patrimonio histórico de Rio Grande do Sul.

Palabras clave: lazer; deporte; modernidad; cavallos; Rio Grande do Sul.

No dia 2 de junho de 1856, em Santana do Livramento, fronteira do Brasil com o Uruguai, estavam reunidos naturais dos dois países para um evento bastante comum na regiáo: o "jogo das carreiras", corridas de cavalos emparelhados em linha reta e montados por um especialista nessa atividade, conhecido como ginete. No decorrer das carreiras, uma confusão teve lugar. O oriental conhecido por Guerreiro e o alferes da Guarda Nacional brasileira Fortunato 


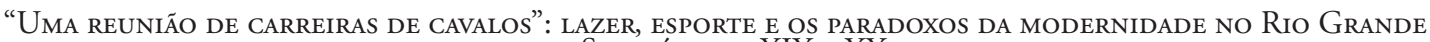
DO Sul, SÉCUlOS XIX E XX

João Manuel Casquinha Malaia Santos, Jonas Moreira Vargas e José Martinho Rodrigues Remedi

Jorge da Silva passaram a se ofender e se agrediram, cada qual apoiado por seu bando. O "castelhano" "Guerreiro feriu dois praças brasileiros e, quando recebeu ordem de prisão, fugiu para o lado uruguaio da fronteira "capitaneando um grupo de desordeiros e bandidos". Ao saber de toda a confusão, o presidente da província do Rio Grande do Sul, Francisco Coelho, não teve dúvidas quanto à melhor medida a ser tomada. Enviou um relatório à Sua Majestade D. Pedro II comunicando a decisão de "proibir o jogo de carreiras sobre toda a linha das nossas fronteiras, para evitar as numerosas reunióes que elas produzem, e que sempre dão lugar a graves desordens, principalmente entre os indivíduos dos dois países". ${ }^{5}$

O “jogo das carreiras" é uma prática habitual em regiōes de todo o Pampa gaúcho, aí incluídas áreas da Argentina, do Brasil e do Uruguai. O que no Rio Grande do Sul é conhecido como carreira em cancha reta, no Uruguai e na Argentina é conhecido como "carreras cuadreras" (HORA, 2014). O "Dicionário do Cavalo" define a carreira como a "disputa entre cavalos de corrida em cancha reta, geralmente em distâncias que variam de duas a seis quadras" (BOSSLE, 2014, p. 70). Por toda a região do Prata, há registros de corridas com a utilização de cavalos em pistas retas e valendo apostas pelo menos desde o início do século XIX. Proprietários de cavalos desafiavam-se uns aos outros para corridas com os animais emparelhados. Um número considerável de pessoas se reunia para ver as corridas e apostar para saber qual seria o cavalo vencedor. Um árbitro dava a largada para garantir que os cavalos saíssem ao mesmo tempo. Outro árbitro ficava na linha de chegada para verificar qual cavalo chegava primeiro. Uma festa com música, apostas, ostentação de poder, exibição de masculinidade e muita bebedeira. Por isso, era também um lugar de muita tensão. Constantemente, apostadores não concordavam com a marcação dos árbitros, acusavam trapaças pelos cavaleiros ou simplesmente não aceitavam o resultado. Outras vezes, antigas rixas eram ali resolvidas. Eram muitos os motivos que faziam com que o evento das carreiras em cancha reta descambasse para agressôes, muitas vezes culminando em mortes.

Desde o período colonial, a regiấo mais ao sul do Brasil e a regiâo do Prata se notabilizaram pela criação de cavalos. As ricas pastagens do Pampa gaúcho foram um fator importante para essa configuração. O fato de o cavalo ser elemento importante de transporte até a chegada da ferrovia (que se deu apenas na segunda metade do XIX) e também de defesa para o exército, principalmente na região de fronteira, fez com que a criação de cavalos se tornasse um elemento importante na cultura gaúcha (GOULART, 1964). Esses fatos são importantes para entendermos toda a pujança do fenômeno do lazer e do esporte hípico nesta região do país. No caso das carreiras em cancha reta, essa cultura atrelada ao cavalo na regiáo foi fator crucial por nos legar importantes registros dessas práticas em um número variado de fontes.

\footnotetext{
${ }^{4}$ Regionalismo do Sul do Brasil usado para designar os habitantes e o que é natural da Argentina e do Uruguai (HOUAISS; VILLAR, 2007, p. 647).

${ }_{5}^{5}$ Relatório do Presidente da Província de São Pedro do Rio Grande do Sul, Jeronymo Francisco Coelho na abertura da Assembleia Legislativa Provincial. Porto Alegre: Typographia do Mercantil, 1856, p. 17 e 18.
} 


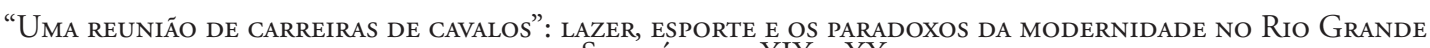
DO SUl, SÉCULOS XIX E XX

João Manuel Casquinha Malaia Santos, Jonas Moreira Vargas e José Martinho Rodrigues Remedi

O fenômeno das carreiras em cancha reta nos ajuda a pensar questóes ligadas ao lazer de pessoas de diferentes grupos sociais em zonas rurais ou nas periferias das cidades. Mostra toda uma cultura de práticas lúdicas ligadas ao cavalo e a comunhão desse hábito por parte de pessoas de diferentes nacionalidades. Além disso, proporciona refletirmos sobre sua permanência frente à chegada das atividades esportivas conhecidas como modernas, principalmente o turfe, modalidade que se instalou aos poucos na Argentina, no Brasil e no Uruguai durante o século XIX.

O turfe é um esporte surgido no século XVII, na Inglaterra, que se espalhou pelo mundo a partir do século XIX. Cavalos montados por jóqueis disputam corridas em uma pista circular de grama (daí o nome do esporte em inglês, turf) ou de areia. Nas corridas, os cavalos são separados por faixa etária, os tempos são cronometrados e há prêmios para os três primeiros colocados de cada corrida. O esporte era organizado a partir de clubes ou até mesmo sociedades anônimas. Havia cobrança de ingressos ao público que ia assistir e sistema de apostas legalizado. Geralmente, havia grande participação popular na assistência e como mão de obra para a organização dos eventos.

A proposta deste trabalho é analisar aspectos do passado das carreiras em cancha reta no Rio Grande do Sul durante os séculos XIX e XX, considerando-o em suas relaçôes com o lazer, com o esporte e com a modernidade. Objetivamos pensar como se dáo as relaçóes entre o tradicional e o moderno a partir da utilização de uma gama variada de documentação que nos ajuda a compreender este fenômeno do lazer, dialogando com a incorporação ou a resistência a elementos da modernidade. Com isso, pretendemos mostrar algumas questôes paradoxais da incorporação dos elementos modernos em relação às práticas lúdicas.

Dentre essas fontes, foram utilizados periódicos publicados nas cidades do Rio Grande do Sul, editados por membros da elite das cidades gaúchas. Por conta dessa característica, esses periódicos serấo vistos como propagadores dos valores modernos e com objetivo de estimular práticas consideradas símbolos da modernidade, como eram considerados os esportes, principalmente o turfe. Também foi utilizada a documentação do governo em suas mais diversas esferas. São documentos como os relatórios dos presidentes da Província de Sáo Pedro do Rio Grande do Sul, ou ainda diversas leis que regulamentavam as carreiras, inclusive leis orçamentárias e códigos de postura, que nos mostram a visão do Estado sobre as carreiras, a necessidade de regulação dessa atividade e a possibilidade de taxação dela, gerando mais receita para o poder público. Foi utilizada também uma vasta gama de obras literárias, que nos ajudam a conhecer melhor o fenômeno em si e a compreender um conjunto de símbolos decantados como próprios das populações da regiấo. Outro conjunto importante de fontes foram os processos-crime, tanto do período imperial quanto do período republicano. As inúmeras descrições de práticas violentas nas pistas de cancha reta na documentação anteriormente citada nos levaram a buscar pistas nos processos-crime. Essas fontes puderam nos mostrar caracterizaçôes dos eventos, suas localizaçôes, 


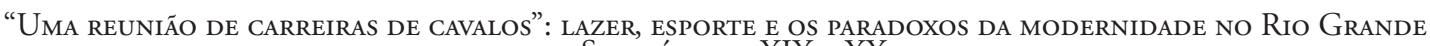
DO Sul, SÉCUlOS XIX E XX

João Manuel Casquinha Malaia Santos, Jonas Moreira Vargas e José Martinho Rodrigues Remedi

os montantes apostados nas corridas, a configuração social dos participantes, entre outras questôes ilustradas a partir de descriçôes de crimes (agressôes e assassinatos) fornecidas por réus, testemunhas e inspetores de polícia.

\section{O outro lado da modernidade}

Na segunda metade do século XIX, grandes cidades brasileiras e da América Latina passaram a ansiar pelos chamados "ares da modernidade", um processo de profusão da industrialização, da urbanização, de novas relações de trabalho, da constituição de novos hábitos importados das grandes cidades europeias. Novas práticas sociais modernas surgiram como fruto de uma nova divisáo do tempo entre aquele destinado ao trabalho e aquele destinado ao não trabalho, parte dele dedicado ao lazer e aos esportes (MELO, 2010).

Quando se observam aspectos do lazer e dos esportes a partir do prisma da modernidade, a postura predominante é a adoção de uma concepção em que as transformações modernizadoras são o parâmetro para a compreensão dos novos hábitos relacionados ao lazer. Os clubes de corridas de cavalo, por exemplo, eram uma novidade que havia se espalhado pelas principais cidades europeias e da América. O processo teve início no final do século XVII, no Reino Unido. As elites britânicas organizavam clubes para a prática do esporte conhecido como turfe, com corridas em pistas ovais, marcação de tempo, premiação em dinheiro aos vencedores e instituição de um mercado legal de apostas. Entretanto, foi no final do século XVIII e ao longo do século XIX que a elite ao redor do mundo ocidental, de um modo geral, passou a organizar massivamente clubes de corridas não apenas como opção de entretenimento, mas como possibilidade de investimento.

$\mathrm{Na}$ América do Sul, as elites também passaram a se organizar para a realização desse tipo de entretenimento. Grupos de criadores de cavalo, principalmente na regiáo do Prata, não tardaram a perceber este fenômeno que reunia multidóes e altas somas de dinheiro envolvido em prêmios e apostas. No Brasil, houve várias tentativas esporádicas na virada da primeira para a segunda metade do século XIX, mas a primeira cidade a ter um clube de corridas de maneira relativamente estável foi o Rio de Janeiro (1868) (BLAY, 2000), seguida de Pelotas (1870), Curitiba (1873), São Paulo (1875) e Porto Alegre (1877). O mesmo fenômeno acontecia também em cidades como Buenos Aires (1849) e Montevidéu (1874).

A prática se disseminou com bastante força na ainda Província de São Pedro do Rio Grande do Sul. Era uma região onde se concentrava a maior parte dos criadores de cavalos do país. Para além das já citadas Porto Alegre e Pelotas, muitas outras cidades fundaram clubes de corridas, como Santa Maria, São Leopoldo, Novo Hamburgo, Taquara, Triunfo, Rio Grande, Bagé, Montenegro, Taquari, Alegrete, entre outras (COSTA, 1920). As corridas reuniam criadores da elite local, atraíam a atenção da imprensa e uma multidão de aposta- 


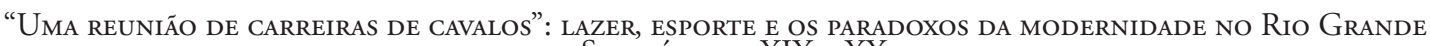
DO Sul, SÉCUlOS XIX E XX

João Manuel Casquinha Malaia Santos, Jonas Moreira Vargas e José Martinho Rodrigues Remedi

dores. Tudo legalizado e com apoio das instâncias governamentais, assim como ocorria nas principais cidades europeias e norte-americanas.

Não abordaremos os processos sociais de produção da teia urbana em uma sociedade que se transformou, no decorrer do século XIX até princípios do século XX, de uma economia pastoril e escravista em uma economia capitalista com setores industriais cada vez mais marcantes. ${ }^{6}$ No entanto, apesar da complexidade das transformaçôes urbanas ocorridas, foi recorrente a intromissão do rural no urbano, com a presença constante de cavalos nas áreas centrais e arrabaldes desde as cidades maiores como Porto Alegre e Pelotas até as pequenas localidades. Foi marcante a presença dos cavalos e, também, dos espaços das corridas nos debates sobre a modernidade que se desejavam e as permanências do passado rural. ${ }^{7}$

Geralmente, os estudos que procuram entender a formação de clubes de corridas de cavalo tentam compreender essa atividade como uma espécie de parâmetro da modernidade (HUGGINS, 2015). A adoção dessa prática fora da Europa seria a adoção de uma atividade moderna pelas elites locais, adotando mais um hábito demonstrativo de seu processo civilizador. Um dos teóricos mais utilizados para esse tipo de abordagem é Norbert Elias, que procura mostrar como práticas populares foram enquadradas pelo poder público e pela elite, passando por aquilo que o autor chamou de "processo civilizador" (ELIAS, 1993 e 1994). Desse modo, muitas das análises fazem com que as ambiguidades, as permanências e mesmo as resistências a esse processo sejam subestimadas. Uma análise sobre as carreiras em cancha reta pode suprir essa lacuna, uma vez que

A abordagem predominante sobre a modernidade, bem como sobre a relação entre lazer e modernidade, tende também a desprezar interaçōes entre sociedades, subsumindo uma variedade de histórias locais numa narrativa hegemônica, homogênea e de certo modo evolucionista. Todavia, a modernidade e as suas práticas, incluindo aí o lazer, constituem processos históricos de longo prazo, com temporalidades diversas e com origens múltiplas (DIAS, 2018, p. 19 e 20).

Tratando dos "paradoxos da modernidade" e da "tradição moderna", Compagnon aponta para um aspecto peculiar da narrativa histórica, fundada naquilo que prevaleceu e que se transmitiu. Observar a historicidade do fenômeno das carreiras em cancha reta auxilia na compreensão de que "possivelmente a face oculta de cada modernidade seja justamente a mais importante" (COMPAGNON, 2010, p. 12). A partir dessas provocaçôes, procuramos pensar nas ambiguidades da modernidade, iluminando as maneiras pelas quais atividades como as carreiras em cancha reta dialogavam com as várias tentativas de racionalização da

\footnotetext{
${ }^{6}$ Ver mais sobre as transformaçōes urbanas no Brasil em Abreu (2001); e, para o caso do Rio Grande do Sul, em Soares (2007).

${ }^{7}$ Sobre o debate da modernizaçáo urbana no Rio Grande do Sul e as permanências do rural (no qual, constantemente, aparecem os cavalos e as corridas de cavalos), ver Pesavento (2002) e Monteiro (1995).
} 


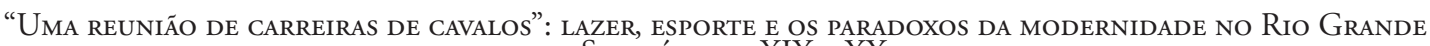
DO Sul, SÉCUlOS XIX E XX

João Manuel Casquinha Malaia Santos, Jonas Moreira Vargas e José Martinho Rodrigues Remedi

organização das práticas lúdicas por parte dos agentes das transformaçôes modernizadoras, como eram considerados os clubes de corrida. Nesse diálogo com o turfe, captar aspectos do passado e de permanência no presente das carreiras é mostrar uma história em que se valorize o tradicional como aquilo que prevaleceu. Ou se não prevaleceu, com certeza se transmitiu. No caso do Rio Grande do Sul, podemos dizer que são poucos os clubes de corridas onde ainda se pratica o turfe. E as carreiras em cancha reta continuam a ser muito praticadas por todo o estado.

Podemos pensar nestes diálogos entre as carreiras e o turfe como a proposta de Guttmann (1978) para observar a passagem de determinadas práticas lúdicas para esporte. Para esse autor, há um conjunto de sete elementos que um fenômeno deve conter para ser considerado um esporte: secularizaçáo; igualdade de oportunidades para competir e de condiçóes de competição; especialização de papéis; racionalização; organização burocrática; quantificação; e busca de recordes. Ao longo de sua história e face às benesses dadas pelo Estado às organizaçóes esportivas ligadas à pratica do turfe, muitas foram as tentativas de colocar as carreiras como um esporte. No entanto, as carreiras permaneceram praticamente fora dessa regulação e muito mais atreladas a uma prática mais espontânea e não esportivizada.

Pensar a historicidade e a permanência das carreiras em cancha reta é pensar nos diálogos entre a instauração de práticas de lazer da modernidade, como o turfe, e a manutenção de práticas de lazer ligadas a tradiçóes locais, como as carreiras. Se o turfe é moderno e mereceu já a atençấo de um considerável número de estudos ${ }^{8}$, há ainda uma lacuna para que se faça uma história das ambiguidades dos fenômenos considerados modernos. Histórias como as das carreiras em cancha reta.?

\section{As carreiras em cancha reta}

A presença das carreiras nas fontes utilizadas para este trabalho revela uma atividade que reunia um número grande de pessoas, das mais diferentes camadas da sociedade, com apostas, disputa de prêmios em dinheiro, venda de bebida alcoólica e comida ao público presente e muitos desentendimentos, gerando até mesmos graves crimes. São fontes de diferentes naturezas e de períodos distintos que nos permitem apreender o fenômeno das carreiras na chamada longa duração. Desse modo, apesar dos registros serem produzidos em diferentes contextos, a permanência das carreiras nestes nos mostra a perenidade do fenômeno, ainda que ele tenha passado por inúmeras mudanças ao longo do tempo.

\footnotetext{
${ }^{8}$ Apenas para citar alguns exemplos: Vamplew (1976), Roche (2008), Hora (2014) e Melo (2019).

${ }^{9}$ Existem alguns trabalhos realizados que iniciaram o processo de iluminaçáo da temática das carreiras em cancha reta no Rio Grande do Sul, pensando o fenômeno por meio dos periódicos da cidade de Porto Alegre: Pereira; Mazo; Lyra (2010); Pereira; Silva; Mazo (2014).
} 


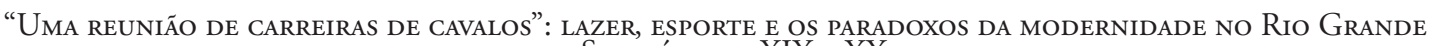
DO Sul, SÉCUlOS XIX E XX

João Manuel Casquinha Malaia Santos, Jonas Moreira Vargas e José Martinho Rodrigues Remedi

As carreiras aparecem com frequência na literatura ambientada na região do Pampa, como um dos instrumentos utilizados na carpintaria romanesca para a demonstraçáo dos valores morais de força e lealdade do herói. É a possibilidade de idealização de um confronto equilibrado dentro de regras estabelecidas rigidamente em códigos tradicionais de conduta. De toda forma, as carreiras em cancha reta se apresentam como momentos-chave nos quais o herói e/ou o vilão são testados em seus atributos éticos e morais, como o uso da violência e o vício dos jogos.

De maneira muito breve e fragmentária, é possível citar algumas obras literárias com descriçôes de carreiras em cancha reta passíveis de análise do processo de construção da identidade do gaúcho. Em 1870, temos diversas carreiras disputadas pelo personagem Manuel Canho em $O$ gaúcho, de José de Alencar (1982) - pode-se dizer que o livro todo é uma carreira vertiginosa empreendida pelo personagem. Logo depois, Apolinário Porto Alegre (1927 [1872]) mostra em seu romance $O$ vaqueano, vindo à luz na forma de folhetim, uma carreira em que há trapaça e brigas entre os personagens principais. Oliveira Bello (1887) trazia personagens com grande apreço por seus cavalos e os coloca em diversos momentos em disputas, inclusive em inusitadas cavalhadas ${ }^{10}$ na Província de São Paulo. Já no escritor Simões Lopes Neto, em seus Contos gauchescos, de 1912, em "Negro Bonifácio" aparece o conflito durante carreiras entre um negro altivo e valente com seus oponentes brancos (LOPES NETO, 1988). Já com as influências modernistas temos em Campo fora (1934), de Ciro Martins, o conto "Alma gaudéria", em que a descrição de uma carreira em cancha reta serve para mostrar os valores da alma do gaúcho e um pouco da nostalgia dos tempos em mudança. Para finalizar essa breve lista, no clássico da literatura brasileira $O$ tempo e 0 vento, de Érico Verissimo, temos ao longo da obra vários relatos de carreiras em cancha reta, assim como no tomo final o aparecimento dos clubes de corridas no Brasil; no tomo d'O Continente, temos o doutor Carl Winter, personagem estrangeiro, descrevendo o universo das carreiras:

Entre fascinado e assustado, Winter assistira a várias carreiras em cancha reta, e mais de uma vez o haviam chamado para atender algum homem que fora estripado num duelo por causa duma "diferença de pescoço" ou de qualquer outra dúvida quanto à decisão do juiz (VERISSIMO, 1963, p. 2).

Como é possível observar, muitas vezes, são não só os ápices da ação romanesca a produzir a principal motivação da vida dos personagens. Especificamente, no caso da gauchesca, a presença das carreiras em cancha reta está na maioria das obras conhecidas.

\footnotetext{
${ }^{10}$ Cavalhadas é uma festa popular com feiçôes religiosas com origem medieval, trazida ao Brasil pelos portugueses ainda no século XVII. Ainda acontecem nas festas do Divino, nas regiốes Sul, Sudeste e Centro-Oeste do Brasil. Ver mais em Schipanski (2009).
} 


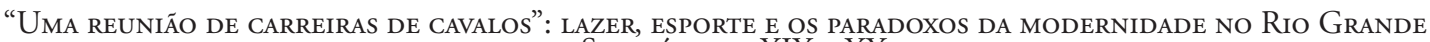
DO Sul, SÉCUlOS XIX E XX

João Manuel Casquinha Malaia Santos, Jonas Moreira Vargas e José Martinho Rodrigues Remedi

Uma das referências mais antigas que dá notícia da presença de carreiras no Rio Grande do Sul, para além das referências literárias, aparece no relatório do Presidente da Província de São Pedro do Rio Grande do Sul, Nunes Pires, do ano de 1837. Em fala à Assembleia Legislativa da Província, o então presidente apresentava a entrada em vigor dos capítulos $3^{\circ}, 4^{\circ}$ e $5^{\circ}$ da Lei do Orçamento de 27 de junho de 1835, com algumas alteraçóes. Dentre elas, estavam as do parágrafo $4^{\circ}$, que suprimia o pagamento de impostos sobre "chapeados e carreiras (vulgo parelhas)". ${ }^{11}$

O cronista José Cândido Gomes, conhecido como "O Estudante"12, publicou uma descrição dessas corridas. Na crônica "Remessa"13 de 4 de abril de 1853, há duas passagens sobre carreiras em Porto Alegre ("O que são as carreiras" e "Ordem de prisão"). "O Estudante" apontava que uma carreira de dois cavalos seria na Várzea, com a distância de três quadras. Na sequência, descreveu o público presente: "Muita gente foi ver: a pé, a cavalo e em carretilha se via povo masculino e feminino, grande e miúdo, claro e escuro: breve, de toda classe, medida e cor". Segue a descriçâo mostrando que figuras proeminentes da sociedade trocavam suas funçóes importantes de médico ou advogado para a de corredores de carreira. Depois de longa espera, o cronista foi avisado que a carreira não mais aconteceria. No entanto, estava presente nas carreiras o "amigo subdelegado do $1^{\circ}$ Districto, que náo é para graças". A crônica mostra que se as carreiras não fossem realizadas na presença do subdelegado, seria grande sinal de desprestígio deste, que havia se dirigido ao local exclusivamente para acompanhá-las: "Para ir tomar ar fresco na várzea não é que se convida um subdelegado". As carreiras aconteceram apenas na parte da noite, com menor presença de público.

Atos violentos aparecem com frequência na documentação sobre as carreiras. No Relatório Imperial do presidente da província José Antônio de Souza Lima para o ano de 1883 constam no item "Segurança Individual" as participaçóes do chefe de polícia e suas ocorrências. Uma dessas ocorrências se dá em Santana do Livramento, "por occasiāo de umas corridas de cavalos", quando João Velasques feriu Manoel Luiz de Assumpção e Dionísio Martins. Velasques foi preso e Assumpção veio a falecer três dias depois dos acontecidos "víctima dos ferimentos que recebeu"14.

Para sorte dos historiadores, muitos desses conflitos ocorridos nos dias de careiras em cancha reta acabaram sendo levados até as delegacias locais, gerando inquéritos e processos judiciais. Uma análise desses autos criminais nos possibilita conhecer melhor o ambiente social no qual ocorriam as carreiras, parte de suas dinâmicas internas e a participação popu-

${ }^{11}$ Relatório do Presidente da Província de São Pedro do Rio Grande do Sul, Nunes Pires, na abertura da Assembleia Legislativa Provincial. Porto Alegre: Typographia do Mercantil, 1837, p. 28.

${ }^{12}$ José Cândido Gomes foi deputado provincial pelo Partido Liberal Progressista entre os anos de 1856 e 1859. Talvez fosse justamente a sua inserção política que lhe desse o conhecimento e o traquejo necessários para que satirizasse as práticas da elite provincial (Cf. WEBER, 1992).

${ }^{13}$ Chronica de Porto Alegre. Terceira Época. $4^{a}$ Remessa, 4 abr. 1853, p. 1-3.

${ }^{14}$ Relatório do Presidente da Província de São Pedro do Rio Grande do Sul, $1^{\circ}$ de jun. 1883, p. 6. 


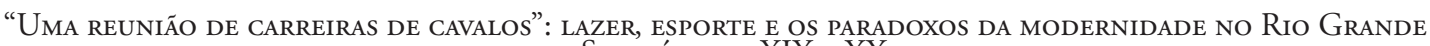
DO Sul, SÉCUlOS XIX E XX

João Manuel Casquinha Malaia Santos, Jonas Moreira Vargas e José Martinho Rodrigues Remedi

lar que as caracterizavam. Além disso, considerando as localidades nas quais os autos foram localizados, é possível perceber que tais práticas ocorriam em todos os cantos da província.

Para o período imperial, a primeira questão a ser apontada é a presença significativa de elementos das classes populares, com destaque para os libertos e os escravos. Em maio de 1873, Dona Felisbina Ferreira da Silva procurou a delegacia de polícia para fazer uma queixa contra Belisário Alves. Segundo ela, o seu escravo chamado Noé estava nas carreiras quando foi atacado por Belisário, que o agrediu e cortou os seus cabelos, sendo interrompido pela multidáo quando estava prestes a degolar o cativo. Os depoimentos das testemunhas são uníssonos em considerar que Belisário andava procurando encrencas, era "turbulento", "provocador", "de maus costumes", trazendo "terror à maior parte da populaçấo do segundo distrito, onde reside". Em sua defesa, Belisário alegou ter reagido a ofensas desrespeitosas de Noé, sendo absolvido. ${ }^{15}$

Em São Martinho, no ano de 1880, também ocorreu fato semelhante, mas dessa vez o escravo foi o réu. Felipe, cativo de Carlos Castilho, "em umas carreiras tendo altercado com Santos Castelhano por causa de corridas de cavalos, deu-lhe um tiro, de que resultou na morte ao mesmo castelhano poucos dias depois". Esse processo, além de demonstrar a presença dos escravos nas carreiras, também se torna importante por outra questáo. $\mathrm{O}$ motivo que provocou a morte do castelhano foi o não pagamento de uma aposta na qual ele perdera para o cativo Felipe. ${ }^{16}$ Assim sendo, engana-se quem pensa que os escravos eram meros espectadores nos dias das carreiras. Alguns processos indicam que muitos também realizavam as suas apostas. Em Bagé, no ano de 1885, Joáo, escravo de Servelo Pereira da Silva, envolveu-se em uma briga por conta das carreiras, ocasião em que foi ferido. Conforme o próprio João, "achando-se em uma reunião de carreiras de cavalos, que teve lugar no terceiro distrito, às três horas mais ou menos da tarde, jogou uma parada com o moço Joáo Lemes e [...] deu para depositar quinhentos réis em papel”. Joáo perdeu a carreira e como a aposta era de uma quantia menor, pediu o troco dos quinhentos réis que havia dado, mas não o obteve. Seguiu-se uma discussão e "neste interim alguém pegou nas rédeas de seu cavalo, que era novo, e empinou-se obrigando-o a apear-se, e em seguida veio João Lemes que se tinha apeado também e com uma faca grande na mão o acometeu". ${ }^{17}$

Além de evidenciar as apostas realizadas por escravos, o documento citado também deixa claro que o cativo João frequentava as carreiras com o seu próprio cavalo. Não era táo raro alguns cativos possuírem cavalos, principalmente no Rio Grande do Sul. O direito dos escravos em adquirirem certos bens fazia parte da política de domínio senhorial no Brasil escravista, segundo a qual os cativos possuíam certa autonomia para tentar juntar pecúlio com vistas a conquistar sua liberdade. ${ }^{18}$ Os registros cartoriais da província apresentam mui-

\footnotetext{
${ }^{15}$ Processo-crime n. 3.831, m. 99, Bagé, $1^{\circ}$ Cartório do Cível e Crime, 1873 (APERS).

${ }^{16}$ Processo-crime n. 871, m. 28, São Martinho, $1^{\circ}$ Cartório do Cível e Crime, 1880 (APERS).

${ }^{17}$ Processo-crime n. 4.220, m. 111, Bagé, $1^{\circ}$ Cartório do Cível e Crime, 1885 (APERS).

${ }^{18}$ Cf. Reis (1989). Atualmente, a historiografia a respeito da escravidão já não questiona mais essa autonomia
} 


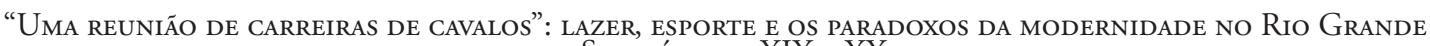
DO Sul, SÉCUlOS XIX E XX

João Manuel Casquinha Malaia Santos, Jonas Moreira Vargas e José Martinho Rodrigues Remedi

tos casos de cativos que conquistavam a sua liberdade pagando seus senhores com cavalos. Em 1848, no município de Sáo Borja, o escravo Simplício comprou a sua liberdade por 400 patacôes de prata, valor pago em "cavalos mansos e éguas" que entregou ao seu senhor. Em 1863, em Uruguaiana, o pardo Manoel comprou a sua liberdade pagando $192 \$ 000$, dos quais $112 \$ 000$ foram quitados com a entrega de seis cavalos e uma égua. ${ }^{19}$

Assim sendo, é provável que muitos dos escravos que possuíam cavalos os levassem inclusive para correrem nas carreiras. Foi o que aconteceu em Taquari, em agosto de 1864. Manoel, escravo de José Antônio Lopes, estava com o seu cavalo nas carreiras do município quando brigou com o liberto Manoel Casemiro da Costa, que lhe agrediu fisicamente várias vezes. Levado à Delegacia, o liberto defendeu-se, dizendo

que estando ele interrogado em umas carreiras onde também se achava o preto Manoel, em ocasiáo que ele interrogado quis fazer uma aposta contra um cavalo do preto Manoel, este chegou-se e lhe disse que não jogasse contra seu cavalo, ao que ele interrogado declarou que era sua vontade jogar a favor do outro cavalo e que além disso o dinheiro era seu.

O liberto acrescentou que já havia tido antigas desavenças com o preto Manoel em outras carreiras nas quais ambos se encontravam. ${ }^{20}$

Uma análise mais atenta do emaranhado de depoimentos contidos nos processos nos possibilita vislumbrar todo um ambiente social no qual as carreiras em cancha reta estavam inseridas. Não é difícil imaginar que se escravos e libertos frequentavam tais locais de lazer, a presença de homens livres pobres devia ser mais comum ainda. As corridas atraíam gente de todo o tipo em busca de lazer e divertimento. Não é coincidência que muitos dos crimes narrados tenham acontecido nas tardes de domingo, dia de folga de boa parte dos trabalhadores, inclusive dos escravos (que negociavam intensamente tais momentos de descanso com seus senhores). Outra questão importante diz respeito à grande presença de público nesses eventos. Os depoimentos sempre revelam haver muitas pessoas no local das carreiras, não sendo raro a presença de mulheres.

Em alguns processos também é possível verificar estrangeiros entre as testemunhas, como portugueses, espanhóis, mas principalmente os chamados "castelhanos". Assim sendo, se entre as elites do turfe as trocas de informaçóes e as relaçóes sociais entre brasileiros, argentinos e uruguaios foram intensas, as camadas mais pobres pareciam vivenciar esse mes-

relativa e uma série de pesquisas tem revelado que tais práticas eram comuns em todo o Brasil. Para o caso do Rio Grande do Sul e de como os cativos podiam ter rebanhos vacuns e cavalares além de suas pequenas lavouras, ver, por exemplo, Matheus (2012).

${ }^{19}$ ARQUIVO PÚBLICO DO ESTADO DO RIO GRANDE DO SUL, v. 2, p. 960; 1.193. Para outros casos como esse, ver ARQUIVO PÚBLICO DO ESTADO DO RS. Documentos da escravidão, catálogo seletivo de cartas de liberdade, acervo dos tabelionatos do interior do Rio Grande do Sul. Porto Alegre: CORAG, 2006, v. 1 e 2.

${ }^{20}$ Processo-crime n. 2.110, m. 29, Taquari, Cartório Cível e Crime, 1865 (APERS). 


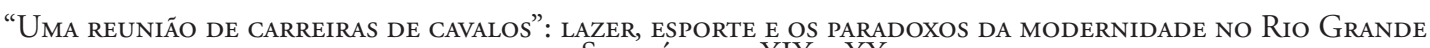
DO Sul, SÉCUlOS XIX E XX

João Manuel Casquinha Malaia Santos, Jonas Moreira Vargas e José Martinho Rodrigues Remedi

mo gosto pelas corridas de cavalos, fazendo parte da cultura popular rural dos três países. A presença de peóes e trabalhadores castelhanos nas estâncias rio-grandenses também foi comum no período e, assim, a convivência entre eles nos espaços de lazer não causa surpresa. Soma-se a isso o fato de que em alguns autos de processos fica evidente que junto às carreiras sempre havia uma pequena venda, na qual os frequentadores consumiam bebidas alcoólicas e seguiam no seu divertimento. Inclusive, muitos dos réus quando cometeram seus crimes estavam embriagados. Não é difícil supor que essas vendas eram o ponto de encontro tanto de trabalhadores locais quanto de jogadores, apostadores e andarilhos que vagavam por aquelas vastas fronteiras.

É importante também ressaltar que as carreiras, ao menos no século XIX, se constituíam em um espaço de lazer frequentado majoritariamente por homens. Em apenas um processo criminal uma mulher foi mencionada como estando presente no momento do ato, o que é bastante revelador. $\mathrm{O}$ trabalho na pecuária e a ocupação de peão de estância eram tarefas exercidas por homens e a sociabilidade em meio às carreiras, assim como o mundo das apostas e desafios entre fazendeiros e ginetes, também funcionavam como momentos propícios para a demonstração da masculinidade e a valentia que se esperava desses homens do campo. Nesse sentido, parece-nos que, com o advento da modernidade, a criação dos jockeys clubes e a elitização das práticas desportivas ligadas ao turfe ofereceram um maior espaço para que as mulheres de famílias de elite, devidamente acompanhadas de seus esposos ou pais, frequentassem tais locais de competição.

Tais características presentes nos processos-crimes do período imperial permaneceram praticamente inalteradas em documentaçáo dessa natureza no período republicano, a despeito da presença de escravos. As carreiras atraíam vários elementos das camadas populares e também eram espaço de lazer de criminosos e sujeitos considerados bandidos locais. Um dos processos analisados parece ter relação com tal fenômeno social. Em 1898, em Pelotas, Nabor Caldeira foi preso enquanto assistia às carreiras no $3^{\circ}$ distrito do município. No seu depoimento, ele dizia ser solteiro, 34 anos e jornaleiro. De acordo com o interrogatório, Nabor teria sido reconhecido pelo delegado de polícia em meio à multidáo e levado para a prisão, pois era procurado por suspeita de ter cometido um homicídio. ${ }^{21}$

$\mathrm{Na}$ cidade de Santa Maria, um número elevado de crimes em ambientes de carreira teve lugar na primeira metade do século XX. O desenvolvimento da ferrovia e a posição de entroncamento ferroviário trazia à cidade uma característica peculiar de elevado fluxo de pessoas e a presença de uma extensa zona rural. Este parece ter sido um cenário propício para a disseminação de atividades ligadas às carreiras em cancha reta.

Em 1914, em umas carreiras acontecidas na cancha da estação Sáo Pedro, em Santa Maria, João Candido vingou a morte de seu irmão, assassinando Angelino Aniceto Chagas. Em depoimento, o criador de animais de 35 anos afirmou que o fez, pois, "a polícia nada havia

${ }^{21}$ Processo de Habeas Corpus, n. 1.498, m. 47, 1 Cartório do Cível e Crime, Pelotas, 1898. 


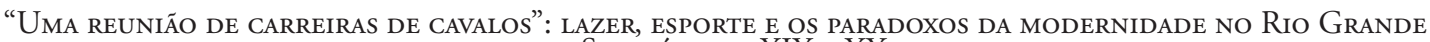
DO Sul, SÉCUlOS XIX E XX

João Manuel Casquinha Malaia Santos, Jonas Moreira Vargas e José Martinho Rodrigues Remedi

feito". Ao chegar às carreiras, João viu Angelino e ouviu-o gritar: "Eu já matei um índio e mato outro". João foi até Angelino e perguntou: "Entáo bandido, já mataste um e agora queres matar outro?”. Sem mais conversa João Cândido puxou seu revólver e deu quatro tiros em Angelino. ${ }^{22}$

No ano de 1922, em umas carreiras em Santa Maria, estava presente Fioravante dos Santos, conhecido como Flores, agricultor e analfabeto. Flores tinha "maus precedentes" e era conhecido na polícia, identificado como "gatuno de cavalos" e tido no $7^{\circ}$ distrito como "desordeiro habitual". A determinada altura, arrumou confusão com o uruguaio "Miguel de tal". Quando já estavam empunhando armas, dois homens tentaram apartar a briga e Flores disparou contra eles. Um dos tiros acertou Pedro Roque no cotovelo, causando-lhe grave lesão. Flores fugiu, "fazendo ainda diversos disparos contra alguns populares que foram ao seu encalço". Ao longo do processo, várias testemunhas são ouvidas. São todos homens, entre 20 e 45 anos de idade, a maioria agricultores, que afirmavam estar a assistir carreiras em frente à "bodega" de Prudêncio Machado, onde costumeiramente "a borracheira era grande". ${ }^{23}$

Em 1929, uma tentativa de homicídio foi relatada pelo Subdelegado Lisbino Martins Alves. De acordo com o relatório preliminar, Egydio dos Santos, "indivíduo de maus precedentes", agredira a relho João Augusto Francisco da Costa por não ter ele apostado consigo em uma carreira. João tentou defender-se com uma pequena adaga ao que Egydio puxou uma faca e um revólver, disparando diversas vezes, acertando três tiros em João e fugindo em seguida. As testemunhas eram homens, todos agricultores com idades entre 21 e 65 anos. Todos foram unânimes em apontar Egydio como um homem perigoso e que já havia sido expulso de Sáo Borja e da Subintendência do Rincáo do Claro por ali ser considerado "desordeiro, bandido e elemento perigoso". ${ }^{24}$

O caso do inspetor de polícia Manoel Palmeira que, em 1913, assassinou Florêncio Severo, em São Pedro, onde "se realizavam umas corridas de cavalos", é bastante revelador do envolvimento entre elementos de diferentes grupos sociais nas carreiras. Florêncio estaria "embriagado, injuriando com obscenidades uns e outros, e provocava distúrbios". Manoel afirmava estar presente às carreiras "para manter a ordem por ali" e que teve "de mais de uma vez durante a diversáo de chamar Florêncio à ordem e sempre que o fazia era desobedecido e injuriado pelo mesmo". A confusão entre os dois se arrastou para depois do evento. Manoel foi até a casa de Florêncio e matou-o à frente da esposa. Apesar do inspetor ser inocentado por legítima defesa e algumas das testemunhas afirmarem que Florêncio quando bebia se tornava um homem perigoso, a esposa de Florêncio, Rufina Severo, acusou Manoel

\footnotetext{
${ }^{22}$ Processo-crime n. 090, Santa Maria, Escrivania do Jury e Execuções Criminaes de Santa Maria, 1914 (Arquivo Histórico Municipal de Santa Maria-AHMSM).

${ }^{23}$ Processo-crime n. 251, Santa Maria, Escrivania do Jury e Execuçóes Criminaes de Santa Maria, 1922 (AHMSM).

${ }^{24}$ Processo-crime n. 381, Santa Maria, Escrivania do Jury e Execuçóes Criminaes de Santa Maria, 1929 (AHMSM).
} 


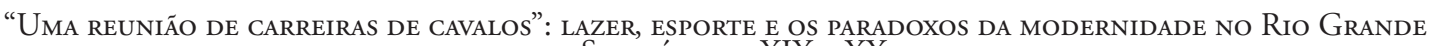
DO Sul, SÉCUlOS XIX E XX

João Manuel Casquinha Malaia Santos, Jonas Moreira Vargas e José Martinho Rodrigues Remedi

de matar seu marido a sangue frio, e outra testemunha acusava Manoel Palmeira não apenas de apostar nas carreiras, mas também de organizar apostas. ${ }^{25}$

Assim sendo, nos parece que o ambiente das carreiras combinava momentos de muita diversão e sociabilidade com outros de grande tensão, demonstração de masculinidade e extrema violência. Agressóes físicas com um diverso leque de instrumentos (nos processos temos o uso de facas, facóes, pistolas, porretes, boleadeiras, tesouras, pedras e relhos) e com o próprio uso dos punhos, realizadas por homens muitas vezes embriagados, podiam não revelar um cotidiano violento das carreiras, mas evidenciam o que era possível de acontecer em casos de conflitos ou desavenças por conta das apostas.

No entanto, se os processos-crime nos revelam a participação das camadas populares, o manuseio de periódicos e de documentos privados de famílias da elite gaúcha revelam também a participação desse grupo social nas carreiras. No Rio Grande do Sul, existem muitos trabalhos que se utilizam da correspondência privada entre membros de famílias de elite revelando suas práticas de sociabilidade e lazer no cotidiano das estâncias. ${ }^{26} \mathrm{Um}$ exemplo é o caso de Severino Ribeiro Carneiro Monteiro, filho do Barão de Sáo Borja. Severino, ainda jovem, era constantemente referenciado pela sua família nas correspondências trocadas entre seus avós e seus pais como um rapaz que se perdia nas carreiras, ou seja, gastava muito tempo e dinheiro com tal divertimento, algo comum entre as famílias pecuaristas da fronteira sul (VARGAS, 2010).

As carreiras em cancha reta faziam parte das práticas lúdicas de diferentes grupos sociais. No entanto, no período entre a segunda metade do século XIX e a primeira metade do século XX, houve uma profusão de clubes de corrida no Sul do Brasil. Sob o controle das autoridades, em recintos fechados e com a presença de elementos da elite, o turfe, nova prática lúdica de entretenimento com cavalos em corrida e apostas, apresentava-se como agente transformador da modernidade, opondo-se às carreiras em cancha reta.

\section{A modernidade e as carreiras}

Ao longo do último quartel do século XIX, as principais cidades gaúchas inauguraram seus clubes de corridas. Esses espaços atendiam à formalização de uma prática hípica e se mostravam como um hábito moderno. Os clubes deveriam ser registrados e pagar impostos. Para minimizar os custos, buscavam subvençóes públicas para suas atividades. A maior parte desses clubes funcionava como sociedades anônimas, inscritas no Registro do Comércio de sua região, assim como obrigava o artigo 296 da lei n. 556, de 25 de junho de 1850, que regulamentava o Código Comercial do Império do Brasil.

\footnotetext{
${ }^{25}$ Processo-crime n. 062, Santa Maria, Escrivania do Jury e Execuçôes Criminaes de Santa Maria, 1913 (AHMSM).

${ }^{26}$ Ver, por exemplo, Vargas (2010), Farinatti (2010), Menegat (2009) e Barbosa (2009).
} 


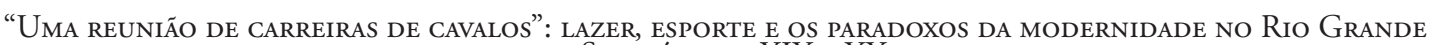
DO SUl, SÉCULOS XIX E XX

João Manuel Casquinha Malaia Santos, Jonas Moreira Vargas e José Martinho Rodrigues Remedi

Já as carreiras em cancha reta existiam décadas antes da inauguração dos primeiros clubes de $\operatorname{corridas}^{27}$ e continuaram existindo com grande frequência. Uma das fontes que pode nos trazer algumas pistas do funcionamento econômico das corridas de cavalo fora dos prados são as listas de previsões e de arrecadações do poder público. Além disso, essas fontes nos revelam tanto a existência das carreiras quanto a sua tentativa de controle por parte do poder público. Em dezembro de 1892, por exemplo, o jornal gaúcho $A$ Federação publicou a previsão de receita ordinária para o ano de 1893 por meio de arrecadação de impostos da Intendência de Porto Alegre ${ }^{28}$. Os itens que aparecem na lista mostram um pouco da vida na cidade e o quanto o poder público de Porto Alegre tinha expectativa de arrecadar com cada uma das atividades que se realizavam na intendência. As cobranças detalham o funcionamento das corridas na capital do Rio Grande do Sul. São cobrados $200 \$ 000$ para organização de corridas em clubes de corridas (os prados) aos domingos, dias santificados ou feriados. Quando se organizavam corridas em dias úteis, a taxa aumentava para $400 \$ 000$ por corrida. Havia também a cobrança de $50 \$ 000$ "por corrida animal cavalar fora dos prados". Fontes desse tipo revelam a coexistência entre carreiras e corridas nos prados em Porto Alegre, além da cobrança de uma taxa muito abaixo daquela para a realizaçáo de uma corrida em um prado.

As fontes nos ajudam a descortinar toda uma cultura lúdica em torno das corridas de cavalo, sejam elas nas canchas retas, sejam nos clubes de corrida, e a perceber a tensão existente entre esses dois mundos, que eram ao mesmo tempo excludentes e complementares. Espécie de lócus de reprodução não linear de aspectos da modernidade europeia, os clubes de corrida cumpriam a função de alimentar os sentidos de modernidade das cidades. Já as carreiras eram locais de um convívio mais fluido entre elementos da elite e das camadas populares, uma vez que a prática não era realizada em clubes fechados e nem havia a separação de público em setores mais ou menos caros das arquibancadas, como nos prados. No entanto, as carreiras eram acusadas de não trazer o grande benefício que só os clubes de corrida podiam trazer: o melhoramento da raça cavalar no Brasil.

Isto pode ser percebido, por exemplo, em uma extensa notícia da Gazeta de Porto Alegre. Na primeira página do dia 15 de maio de $1880^{29}$, o cronista estampa toda a sua felicidade por finalmente Porto Alegre inaugurar, como já havia em São Paulo e em Pelotas, "um club de corridas". Descreveu as carreiras em cancha reta como "a diversão predilecta de todo o verdadeiro filho da província", mas que elas não produziriam a almejada "introdução de animaes de fina raça [...] que muito contribuiráo para melhorar a existente na província”. Esses discursos alinham-se aos proferidos pelos proprietários de cavalos reunidos em torno

\footnotetext{
${ }^{27}$ Apenas para citar um exemplo, o clube de corridas mais antigo do Rio Grande do Sul é o Derby Club Pelotense, inaugurado em 1870. No entanto, há notícias de carreiras na região central de Pelotas atraindo multidóes de pessoas ao menos desde o ano de 1836 (OSORIO, 1962).

${ }^{28}$ Receita Ordinária. A Federação, 29 dez. 1892, p. 2 e 3.

29 "Inauguração do Hippodromo". Gazeta de Porto Alegre, Porto Alegre, 15 maio 1880, p. 1.
} 


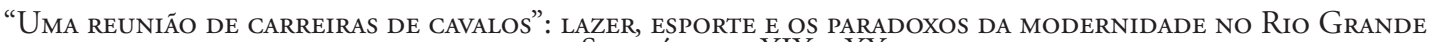
DO Sul, SÉCUlOS XIX E XX

João Manuel Casquinha Malaia Santos, Jonas Moreira Vargas e José Martinho Rodrigues Remedi

do Jockey Club do Rio de Janeiro que buscavam com esse discurso obter as benesses do governo imperial (SANTOS; GIGLIO, 2017). Mesmo afirmando que "a civilização tem suas exigências", o cronista apontou que a prática das carreiras não seria abandonada no novo clube de corridas. Local de produção de um cavaleiro-herói que "parece ligado ao seu animal", um verdadeiro "centauro da campanha", as carreiras seriam reproduzidas também no novo hipódromo. Os diretores do novo empreendimento "não quizerão privar o povo inteiramente de seu antigo sistema" e por isso proporcionariam "uma corrida em cavallos sem sellas, permitindo que os próprios donos montem os seus animaes". Percebe-se o quanto as carreiras em cancha reta assumiam um papel importante no imaginário gaúcho. Por mais que os clubes de corridas pudessem advogar o melhoramento da raça cavalar, não podiam deixar de contemplar as atividades que produziam os "centauros da campanha".

A tensão existente entre a prática das carreiras e a organização de clubes de corrida pode ser observada por meio de uma série de notícias publicadas pelo jornal semanal $A$ Razão, da pequena vila de Encruzilhada, interior do Rio Grande do Sul. De acordo com o jornal local, em 1899, a vila tinha 13 mil habitantes e 10 mil cavalos. ${ }^{30}$ Ao longo desse ano, o jornal noticiou carreiras em cancha reta entre figuras importantes da cidade. O proprietário da Fazenda Santa Rita, palco de inúmeras carreiras da cidade, Antônio Maria Amaro de Freitas desafiou o tenente José Maria da Silva, primeiro suplente do primeiro juiz do primeiro distrito da cidade de Capivary, para uma carreira. A aposta foi de 4:000\$000 (4 contos de réis) ${ }^{31}$, uma pequena fortuna para a época. Para se ter uma ideia, no mesmo ano, o Derby Club do Rio de Janeiro, um dos clubes que distribuía os melhores prêmios na então Capital Federal, pagou de pouco menos de $750 \$ 000$ ao total para os seis páreos das corridas inaugurais do ano de $1899 .{ }^{32}$ Um mês depois da vitória sobre o cavalo do tenente José Maria da Silva, Antônio Maria Amaro de Freitas desafiaria o Coronel Carlos Telles para uma carreira em cancha reta de quatro quadras e novamente a aposta de 4 contos de réis. ${ }^{33}$ Os altos valores faziam com que o cronista do jornal escrevesse: "por isso chama a atenção dos amadores dessa diversão, si é que se pode dar esse nome a táo grande arriscada". ${ }^{34}$

Apesar das somas envolvidas e do sucesso das carreiras em cancha reta, o jornalista de Encruzilhada mostrava sua simpatia com a notícia da possibilidade da chegada de um clube de corridas na vila:

pessoas gradas da nossa sociedade estáo trabalhando com afinco para levarem a efeito a creaçáo de um prado nesta villa, já estando organizado o projeto dos respectivos estatutos. Tal iniciativa

\footnotetext{
${ }^{30}$ A Razão, Encruzilhada, 25 jun. 1899, p. 1.

${ }^{31}$ A Razão, Encruzilhada, 9 jul. 1899, p. 1.

${ }^{32}$ Gazeta de Notícias, Rio de Janeiro, 15 maio 1899, p. 2.

${ }^{33}$ A Razão, Encruzilhada, 13 ago. 1899, p. 3.

${ }^{34}$ A Razão, Encruzilhada, 9 jul. 1899, p. 1.
} 


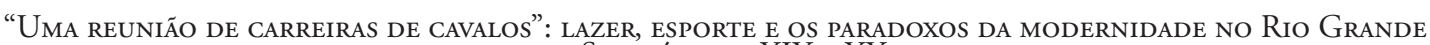
DO Sul, SÉCUlOS XIX E XX

João Manuel Casquinha Malaia Santos, Jonas Moreira Vargas e José Martinho Rodrigues Remedi

é digna dos nossos aplausos e deve ser recebida com louvores pelo honrado comercio desta praça pois que ella encerra uma medida de alto alcance econômico. ${ }^{35}$

Outro caso em que podemos observar diálogos entre as carreiras e o turfe se deu em Santa Maria, no ano de 1919. O jornal Diário do Interior vinha fazendo publicidade às corridas da Sociedade Protetora do Turfe Santamariense (SPTS), mas a temporada de chuvas custava a passar, tornando impraticáveis as corridas. No entanto, no mesmo dia que um evento foi cancelado, o jornal apresentava a seguinte nota, ao lado da que anunciava o adiamento das corridas da SPTS: "Um sensacional desafio entre os cavalos Vigia e Alegrete pela parada de um conto e quinhentos mil réis. Hoje, se o tempo permitir, correrão dois animais de propriedade dos srs. Elo Bicca e Francisco Rocha pela quantia também de um conto de réis" ${ }^{36}$

Nesse diálogo com os elementos de esportivização, um dos exemplos mais claros aparece nas açôes da diretoria do Jockey Club Carazinhense, da cidade de Carazinho, norte do Rio Grande do Sul. Já nas décadas de 70 e 80 do século XX, o clube de corridas da cidade realizava carreiras em cancha reta, com a presença de apostas em dinheiro nos cavalos, mas se recusava a pagar os impostos ao Ministério da Previdência e Assistência Social (MPAS). O MPAS executou a ação e a pista e o terreno do Jockey Club de Carazinho foram a leilão. O prefeito de Carazinho, Sebastião Olegário Haeffner, escreveu uma carta para o procurador do caso fazendo a defesa do clube que dizia ser "a maior entidade social" da cidade e a "maior cancha reta do Brasil”. Na execução, o juiz Leonello Pedro Paludo descreve as alegaçóes dos advogados do clube: que a cancha reta era tradição do Rio Grande do Sul, que os únicos clubes que pagavam previdência no Brasil eram os de São Paulo e do Rio de Janeiro, que havia outras carreiras que também não pagavam. O representante do MPAS apenas respondeu que a questão não era se as corridas eram em reta ou em curva e sim o mercado de apostas. O juiz deu ganho de causa ao Ministério e mandou executar o leilão do terreno do clube que ainda seguiu lutando por sua existência. ${ }^{37} \mathrm{O}$ Jockey Club Carazinhense ainda existe, organiza corridas em cancha reta e a cidade de Carazinho se apresenta como capital nacional do turfe quando organiza essas provas. ${ }^{38}$

É interessante perceber que mesmo com a profusão de clubes de corrida no Rio Grande do Sul ao longo da segunda metade do século XIX e início do XX, a prática das carreiras em cancha reta continuou a coexistir com as corridas nos prados. Pode-se perceber isto em crônicas publicadas já no final da primeira metade do século XX, como por exemplo na edição comemorativa do décimo primeiro aniversário do jornal $A$ Época, de Caxias do Sul, de ou-

\footnotetext{
${ }^{35}$ A Razão, Encruzilhada, 13 ago. 1899, p. 3.

${ }^{36}$ Diário do Interior, Santa Maria, 23 jul. 1917, p. 4.

${ }^{37}$ Ministério da Previdência e da Assistência Social. Fundo: Serviço Nacional de Informações - BR DFANBSB V8.MIC, GNC.AAA.88065489, 1987 (SIAN - Arquivo Nacional, Brasil).

${ }^{38}$ Diário da Manhä, Carazinho, 28 e 29 abr. 2018, p. 7.
} 


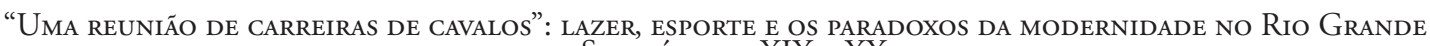
DO Sul, SÉCUlOS XIX E XX

João Manuel Casquinha Malaia Santos, Jonas Moreira Vargas e José Martinho Rodrigues Remedi

tubro de $1949^{39}$. Em uma nota com o título "A carreira", o autor escreveu que a carreira em cancha reta "sempre foi o divertimento predileto dos gaúchos do Rio Grande" e arrematou: "Na campanha, a carreira não perdeu coisa alguma do seu estado primitivo, e continua a ser o ponto de reunião obrigatório da gauchada". O autor descreve que a atividade da cancha reta conta com apostas, corridas de dois ou até de oito cavalos. Desse caráter "primitivo" que o autor destaca, descreve a violência que muitas vezes envolve as canchas. Quando há alguma dúvida sobre a carreira "e que a palavra náo pode dissipar, decide-se ali mesmo, a relho ou a faca, e às vezes, a trabuco".

O mesmo jornal, em 1952, publica um trecho de "Parando Rodeio: páginas soltas de anotaçôes campeiras"40 , de Benito José Fattori, famoso escritor gaúcho. Em um texto com o título "Carreiradas", o autor afirma que no nordeste do estado do Rio Grande do Sul ainda se praticavam muito as carreiras em cancha reta, que "como antigamente não perderam quase nada do seu agreste estado primitivo". E aponta o seu lado de violência quando ocorrem desentendimentos: "Corre facão que é um caso sério". O autor aponta ainda a contemporaneidade das carreiras em cancha reta, afirmando que esta "continua firmemente enraizada na alma do gaúcho e que dificilmente será posta de lado. Qualquer guasca ou índio velho suspira pelas carreiradas". Apesar da permanência de aspectos negativos, essa violência parece ser usada para simbolizar algo muito próprio da "alma do gaúcho".

\section{Considerações finais}

Acreditamos que ainda há caminhos a percorrer neste tipo de investigação. Apresentamos aqui apenas algumas das consideraçóes iniciais sobre um dos aspectos deste fenômeno que são as corridas de cavalo no Rio Grande do Sul. Podemos caminhar em uma direção bastante profícua se conectarmos toda a pujança da produção da pecuária (bovina e equina) gaúcha com as atividades dos proprietários de cavalos nos clubes de corridas e nas carreiras em cancha reta. Observar as carreiras em cancha reta a partir de uma perspectiva das ambiguidades da modernidade nos mostra aspectos desse fenômeno ainda muito pouco trabalhados em pesquisas anteriores sobre as práticas lúdicas. Podemos perceber atividades lúdicas de camadas menos abastadas, como escravos, libertos e brancos pobres ou ainda a transnacionalidade do fenômeno das carreiras.

No entanto, algumas questôes já podemos ter em mente para a realização de novos estudos sobre as carreiras em cancha reta. Antes de mais nada, sabemos que é um fenômeno lúdico que se pratica com sua roupagem mais duradoura (dois ou mais cavalos montados

\footnotetext{
39 "A Carreira". Edição Comemorativa do $11^{\circ}$ aniversário de $A$ Época, Caxias do Sul, 10 out. 1949, p. 34.

${ }^{40}$ FATTORI, Benito José. Parando Rodeio: páginas soltas de anotaçôes campeiras. A Época, Caxias do Sul, 21 set. 1952 , p. 3.
} 


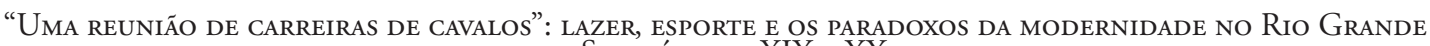
DO Sul, SÉCUlOS XIX E XX

João Manuel Casquinha Malaia Santos, Jonas Moreira Vargas e José Martinho Rodrigues Remedi

por ginetes, correndo em pista reta e com aposta em dinheiro envolvida) desde pelo menos o início do século XIX. Apesar de ser uma prática lúdica que tem lugar desde meados do século XIX até os dias atuais, ela não está imune ao tempo. Os inúmeros diálogos com o turfe e suas tentativas mais ou menos bem-sucedidas de esportivização nos mostram o quanto essa atividade se transformou ao longo do tempo, ao mesmo tempo que busca manter características ligadas ao seu passado. Sabemos também que as carreiras precisaram de alguma forma dialogar com a o turfe. O evento atraía espectadores das mais variadas camadas sociais e a violência foi uma das marcas ligadas a essa prática. Podemos perceber também que essa violência de certa maneira é usada em alguns registros para compor o que se procura mostrar como a "alma do gaúcho".

Do mesmo modo, analisar os diálogos das carreiras em cancha reta com diversos processos de esportivização faz com que seja possível perceber todo um processo de mudanças e permanências do fenômeno. Sem dúvida, alguns organizadores das carreiras em cancha reta, ao longo do século $\mathrm{XX}$, procuraram dialogar com aspectos da esportivização dessa prática lúdica. No clube de Carazinho, por exemplo, organização burocrática, há uma tentativa de racionalização do fenômeno, de quantificação e de busca de recordes ("a maior cancha reta do mundo"). Mas esta parece ser uma tentativa que abarca pouco do fenômeno da cancha reta em sua totalidade. As carreiras em cancha reta continuam sendo praticadas, descritas em textos, músicas e filmes. É possível também perceber que as carreiras seguem existindo e sendo descritas com permanência de elementos ligados aos primórdios desse fenômeno. A atividade transformou-se recentemente em Patrimônio Histórico e Cultural do Rio Grande do Sul, em lei sancionada no ano de $2014 .{ }^{41}$ Se a narrativa moderna do turfe foi a que prevaleceu, pode não necessariamente ter sido a vencedora.

\section{Fontes primárias}

A CARREIRA... A Carreira. Edição Comemorativa do $11^{\circ}$ aniversário. A Época, Caxias do Sul, p. 34, 16 out. 1949.

ARQUIVO PÚBLICO DO ESTADO DO RIO GRANDE DO SUL, v. 2, p. 960; 1.193. ARQUIVO PÚBLICO DO ESTADO DO RS. Documentos da escravidão, catálogo seletivo de cartas de liberdade, acervo dos tabelionatos do interior do Rio Grande do Sul. Porto Alegre: CORAG, 2006, v. 1 e 2.

BRASIL. Ministério da Previdência e da Assistência Social. Fundo: Serviço Nacional de Informações - BR DFANBSB V8.MIC, GNC.AAA.88065489 (Sistema de Informação do Arquivo Nacional, Brasil), 1987.

\footnotetext{
${ }^{41}$ Lei 14.459 de 15 jan. 2014: "Ficam declaradas como bem integrante do patrimônio histórico e cultural do Estado do Rio Grande do Sul as Carreiras de Cavalos em Cancha Reta". Assinada por Tarso Genro.
} 


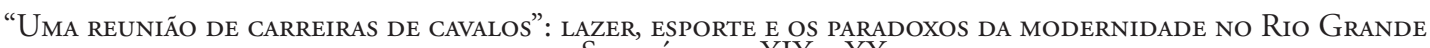
DO Sul, SÉCUlOS XIX E XX

João Manuel Casquinha Malaia Santos, Jonas Moreira Vargas e José Martinho Rodrigues Remedi

CORRIDAS.. Corridas. Diário do Interior, Santa Maria, p. 4, 23 jul. 1917.

DADOS... Dados Estatísticos do Município de Encruzilhada. A Razão, Encruzilhada, p. 1, 25 jun. 1899.

FATTORI, Benito José. Parando Rodeio: páginas soltas de anotaçôes campeiras. A Época, Caxias do Sul, p. 3, 21 set. 1952.

FRIPP, Marcelo. Carazinho, a capital nacional do turfe neste fim de semana. Diário da Manhä, Carazinho, p. 7, 28 e 29 abr. 2018.

INAUGURAÇÃO... Inauguração do Hippodromo. Gazeta de Porto Alegre, Porto Alegre, p. 1, 15 mai. 1880.

NOTAS... Notas Sportivas. A Razão, Encruzilhada, p. 1, 9 jul. 1899.

NOTAS... Notas Sportivas. A Razão, Encruzilhada, p. 3, 13 ago. 1899.

PROCESSO... Processo-crime n. 2.110, m. 29, Taquari, Cartório Cível e Crime (Arquivo Público do Estado do Rio Grande do Sul), 1865.

PROCESSO... Processo-crime n. 3.831, m. 99, Bagé, 10 Cartório do Cível e Crime, (Arquivo Público do Estado do Rio Grande do Sul), 1873.

PROCESSO... Processo-crime n. 871, m. 28, São Martinho, $1^{\circ}$ Cartório do Cível e Crime (Arquivo Público do Estado do Rio Grande do Sul), 1880.

PROCESSO... Processo-crime n. 4.220, m. 111, Bagé, $1^{\circ}$ Cartório do Cível e Crime (Arquivo Público do Estado do Rio Grande do Sul), 1885.

PROCESSO... Processo-crime n. 062, Santa Maria, Escrivania do Jury e Execuçôes Criminaes de Santa Maria (Arquivo Histórico Municipal de Santa Maria), 1913.

PROCESSO... Processo-crime n. 090, Santa Maria, Escrivania do Jury e Execuçôes Criminaes de Santa Maria (Arquivo Histórico Municipal de Santa Maria), 1914.

PROCESSO... Processo-crime n. 251, Santa Maria, Escrivania do Jury e Execuçóes Criminaes de Santa Maria (Arquivo Histórico Municipal de Santa Maria), 1922.

PROCESSO... Processo-crime n. 381, Santa Maria, Escrivania do Jury e Execuçóes Criminaes de Santa Maria (Arquivo Histórico Municipal de Santa Maria), 1929.

PROCESSO... Processo de Habeas Corpus, n. 1.498, m. 47, Pelotas, $1^{\circ}$ Cartório do Cível e Crime (Arquivo Público do Estado do Rio Grande do Sul), 1898.

RECEITA... Receita Ordinária. A Federação, Porto Alegre, p. 2-3, 29 dez. 1892.

REMESSA... Remessa. Chronica de Porto Alegre. Terceira Época, 4a Remessa, p. 1-3, 4 abr. 1853.

RIO GRANDE DO SUL. Relatório do Presidente da Provincia de São Pedro do Rio Grande do Sul, Nunes Pires, na abertura da Assembleia Legislativa Provincial. Porto Alegre: Typographia do Mercantil, 1837. 


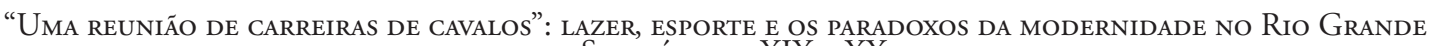
Do Sul, SÉCUlOS XIX E XX

João Manuel Casquinha Malaia Santos, Jonas Moreira Vargas e José Martinho Rodrigues Remedi

RIO GRANDE DO SUL. Relatório do Presidente da Provincia de São Pedro do Rio Grande do Sul, Jeronymo Francisco Coelho na abertura da Assembleia Legislativa Provincial. Porto Alegre: Typographia do Mercantil, 1856.

RIO GRANDE DO SUL. Relatório do Presidente da Provincia de São Pedro do Rio Grande do Sul, José Antonio de Souza Lima, na abertura da Assembleia Legislativa Provincial. Porto Alegre: Typographia do Jornal do Commercio, 1883.

SPORT... Sport: Derby Club. Gazeta de Notícias, Rio de Janeiro, p. 2, 15 mai. 1899.

\section{Referências}

ABREU, Maurício de Almeida. Cidade brasileira: 1870-1930. In: SPOSITO, Maria Encarnação Beltrão (Org.). Urbanização e cidades: perspectivas geográficas. Presidente Prudente: Unesp, 2001.

BARBOSA, Carla. A casa e suas virtudes: relações familiares e a elite farroupilha (RS, 18351845). Dissertação (Mestrado em História), Programa de Pós-Graduação em História, Unisinos, 2009.

BLAY, Jean-Pierre. Gentleman tropical e mundo hípico na cidade do Rio de Janeiro (18621932). In: KERN, Arno Alvarez. Sociedades Ibero-Americanas: reflexôes e pesquisas recentes. Porto Alegre: EDIPUCRS, 2000. p. 77-99.

BOSSLE, Batista. Dicionário do cavalo. Porto Alegre: Martins Livreiro, 2014.

COMPAGNON, Antoine. Os cinco paradoxos da modernidade. Belo Horizonte: Editora UFMG, 2010.

COSTA, Olival (org.) Manual do Turf. São Paulo: Seção Obras do Estado de São Paulo, 1920.

DIAS, Cleber. História e historiografia do lazer. Recorde, v. 11, n. 1, p. 1-26, 2018.

ELIAS, Norbert. O processo civilizador: uma história dos costumes, v. I. Rio de Janeiro: Jorge Zahar Ed., 1994.

ELIAS, Norbert. O processo civilizador: formação do Estado e civilização, v. II. Rio de Janeiro: Jorge Zahar Ed., 1993.

FARINATTI, Luis Augusto. Confins meridionais: famílias de elite e sociedade agrária na fronteira sul do Brasil (1825-1865). Santa Maria: Ed. UFSM, 2010.

GOULART, José Alipio. O cavalo na formação do Brasil. Rio de Janeiro: Editora Letras e Artes, 1964.

GUTTMAN, Allen. From Ritual to Record: the nature of modern sports. New York: Columbia University Press, 1978. 


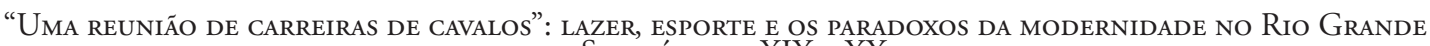
DO Sul, SÉCUlOS XIX E XX

João Manuel Casquinha Malaia Santos, Jonas Moreira Vargas e José Martinho Rodrigues Remedi

HORA, Roy. História del turf argentino. Buenos Aires: Seiglo Veineuno Editores, 2014.

HOUAISS, Antonio; VILLAR, Mauro de Salles. Dicionário Houaiss da Lingua Portuguesa. Rio de Janeiro: Objetiva, 2007.

HUGGINS, Mike. Racing Culture, Betting, and Sporting Protomodernity: The 1750 Newmarket Carriage Match. Journal of Sport History, v. 42, n. 3, p. 322-339, 2015.

MATHEUS, Marcelo Santos. Fronteiras da liberdade: escravidão, hierarquia social e alforria no extremo sul do Império do Brasil. São Leopoldo: Oikos/Unisinos, 2012.

MELO, Victor Andrade de. Lazer, modernidade, capitalismo: um olhar a partir da obra de Edward Palmer Thompson. Estudos Históricos, v. 23, n. 45, p. 5-26, 2010.

MELO, Victor Andrade de. Um hipódromo suburbano: a experiência do Club de Corridas Santa Cruz (Rio de Janeiro - 1912/1918). Topoi: Revista de História, v. 20, p. 157-184, 2019. MENEGAT, Carla. $O$ tramado, a pena e as tropas: família, política e negócios do casal Domingos José de Almeida e Bernardina Rodrigues Barcellos (Rio Grande de São Pedro, Século XIX). Dissertação (Mestrado em História). Programa de Pós-Graduação em História, UFRGS, 2009.

MONTEIRO, Charles. Porto Alegre: urbanização e modernidade. A construção social do espaço urbano. Porto Alegre: EDIPUCRS, 1995.

OSORIO, Fernando L. A cidade de Pelotas. Rio de Janeiro: Editora Globo, 1962.

PEREIRA, Ester L.; MAZO, Janice Z.; LYRA, Vanessa B. Corridas de cavalo em cancha reta em Porto Alegre (1852/1877): uma prática cultural-esportiva sul-rio-grandense. Revista da Educação Física/UEM, v. 21, n. 4, p. 655-666, 2010.

PEREIRA, Ester L.; SILVA Carolina F. da; MAZO, Janice Z. Os primeiros vestígios da esportivizaçáo das práticas equestres em Porto Alegre. Revista Brasileira de Ciência e Movimento, v. 22, n. 2, p. 121-132, 2014.

PESAVENTO, Sandra J. Imaginário da cidade: visôes literárias do urbano (Paris, Rio de Janeiro e Porto Alegre). 2. ed. Porto Alegre: Ed. da Universidade, 2002.

REIS, João José; SILVA, Eduardo. Negociação e conflito. São Paulo: Companhia das Letras, 1989. ROCHE, Daniel. Equestrian Culture in France from the Sixteenth to the Nineteenth Century. Past \& Present, v. 199, n. 1, p. 113-145, 2008.

SANTOS, João M. C. M.; GIGLIO, Sérgio S. O papel da memória na construção da identidade organizacional: a Sociedade Jockey Club (1868-1932) e o "desenvolvimento da riqueza pastoril". Recorde, v. 10, n. 1, p. 1-21, 2017.

SCHIPANSKI, Carlos E. Cavalhadas de Guarapuava: história e morfologia de uma festa campeira (1899-1999). Tese (Doutorado em História), Programa de Pós-Graduação em História, Universidade Federal Fluminense, Niterói, 2009. 


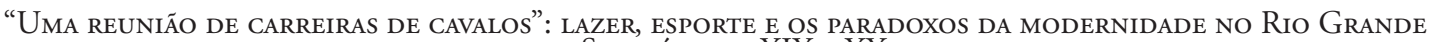
DO SUl, SÉCULOS XIX E XX

João Manuel Casquinha Malaia Santos, Jonas Moreira Vargas e José Martinho Rodrigues Remedi

SOARES, Paulo Roberto Rodrigues. La construcción social de la forma urbana: la ciudad de Pelotas (Brasil) en la transición de los siglos XIX y XX. Scripta Nova. Revista Electrónica de Geografia y Ciencias Sociales, n. 10, 2007.

VAMPLEW, Wray. The turf: a social and economic history of horseracing. London: Allen Lane, 1976.

VARGAS, Jonas M. Entre a paróquia e a Corte: os mediadores e as estratégias familiares da elite política do Rio Grande do Sul (1850-1889). Santa Maria/Porto Alegre: Ed. UFSM/ Anpuh-RS, 2010.

WEBER, Beatriz Teixeira. Código de Posturas e Regulamentação do convívio social em Porto Alegre no século XIX. Dissertaçáo (Mestrado em História), Programa de Pós-Graduaçáo em História, Universidade Federal do Rio Grande do Sul, Porto Alegre, 1992. 